METALLURGY AND FOUNDRY ENGINEERING - Vol. 36, 2010, No. 2

\author{
Paweł Żak*, Janusz Lelito**, Witold K. Krajewski***, Józef S. Suchy****, \\ Beata Gracz*, Michał Szucki*
}

\title{
MODEL OF DENDRITE GROWTH IN METALLIC ALLOYS
}

\section{INTRODUCTION}

Constantly increasing demand for high quality products as tendency to reduction production costs impose the use of innovative and advanced computer modelling techniques. Today's technician is unable to provide a high quality product in a demanded time without the use of computer aided tools. However, increasing competition between manufacturers causes use of basic algorithms becomes insufficient. That is why developers of new technology and computer intended algorithms more often take into account processes that runs at micro- and nano- scale. While computing power is increasing it is possible to get results of good accuracy after reasonable time, even though improved models need much more computational effort.

Predicting the microstructure of modern alloys and composite materials requires a knowledge of differential equations that describe the rate of nucleation, dendrite growth and the alloying elements concentration in the grain and the fluid surrounding it.

Attempts to develop such models have already been undertaken by numerous authors [1-8]. Mentioned authors attempt to analyze the process of nucleation. It is the stage, which has the greatest importance to the formation of casted component microstructure and its properties. Models built by them took into account the various processes that may take place in the metal during the initial stage of crystallization. They try to find the link between the effect of the nucleation rate and growth of existing grains on the latent heat of crystallization release. Partitioning durig solidification leads to build-up or depletion of solute in the liquid adjected to the solid. Mentioned process effects the crystals growth rate because the diffusion in the liquid is main phenomenon that controls the growth rate. As the grains radiuses grows the solid volume fraction grows. This leads to release the latent heat of solidification which affects the rate of undercooling change.

* M.Sc., ** Ph.D., *** Ph.D., D.Sc., **** Prof., Ph.D., D.Sc.: Faculty of Foundry Engineering, AGH University of Science and Technology, Kraków, Poland; e-mail: pawelzak@agh.edu.pl 
In this paper the authors attempt to build a model that could help determine the mutual relationship between the concentration field on the axis joining the center of dendrite and its tip and dendrite growth rate. Prepared model can be useful even in the case of compound alloy while it is possible to reduce it to binary alloy according to additivity rule $[9,10]$. As in Rappaz and Thevoz [2] work it was assumed that dendrite grows inside the spherical envelope of radius $R$, that consists its arms and surrounding liquid. However, in their attempt Rappaz and Thevoz [2] analyzed the heat transfer equation and its sensitivity on dendrites growth rate. In presented work authors assume constant cooling rate. The dendrite tip growth rate is calculated with relationship given by Burden and Hunt [15]. Resultant set of differential equations describes the relations that rules liquid alloy behaviour during crystallization. Those equations can be used to analyze depletion depth as well as concentration change in the melt adjected to the grain. Obtained data can be used to analyze those phenomenons or become complement to build more general nucleation and crystal growth model $[8,11]$.

\section{MODEL DESCRIPTION}

Computations domain is limited to a spherical volume, $V$, of $R_{\max }$ radius in which nucleation event can take place. The temperature change in this volume is small enough that assumption of equal temperature in this region can be made. It was also assumed that new crystal appears in the centre of volume $V$. Liquid that surrounds the grain separates it from the other grains so no impingement of temperature or diffusion fields surrounding grains is possible. That is why no temperature or concentration gradient at the boundary of $V$ volume was assumed. Dendrite grows in its spherical envelope of radius $R$ that consists of solid dendrite and interdendritic melt. Border of this envelope separates grain from extradendritic liquid. The radius of envelope changes as the dendrite tips grow into the extradendritic melt. The concentration near to dendrite tip plays main role during dendrite growth rate calculation. In order to simplify no diffusion profile inside dendrite envelope is calculated. The assumptions mentioned above make it possible to reduce described problem to one-dimensional. Domain of this problem is interval $\left[0, R_{\max }\right]$ located on the axis that joins centre of dendrite with its tip.

\subsection{Compound alloys reduction to binary alloy}

Presented model can be used for compound alloy but computations take place only for binary alloy. As it was shown by Dahle et al. [9] it is possible to reduce compound alloy to binary alloy in terms of calculating diffusion coefficients and growth restriction parameters with additive rule. It was successively used for aluminium alloys [12]. According to additive rule, desired parameter, $K$, can be approximated with following formula:

$$
K=\sum_{i} K_{i} C_{i}
$$

where: $i$ stands for any alloying element present in the melt; $K_{i}$ is the value of approximated parameter for $i^{t h}$ element and $C_{i}[\mathrm{wt} \%]$ is this element concentration in alloy. 
Additive rule, as described in Eq. (1) was successively applied during grain refinement modelling which was based on free growth model $[3,10]$.

\subsection{New grain initiation}

Model concerns one dendritic grain that grows in its envelope within spherical volume $V$ of $R_{\text {max }}$ radius. New grain initiation takes place in the centre of $V$. Heterogeneous nucleation is taken into account. Grain grows from single inoculant particle of radius $R$. This radius is defined as the average size of inoculant particles added to the melt. According to free growth model this value allows to determine the undercooling (temperature) in spatially isothermal $V$ sphere. It is the critical undercooling necessary for free growth at the particle of $2 R$ diameter [3]:

$$
\Delta T_{f g}=\frac{2 \sigma_{s l}}{\Delta S_{V} R},
$$

where: $\sigma_{s l}\left[\mathrm{~J} \cdot \mathrm{m}^{-2}\right]$ is the solid/liquid interfacial energy; $\Delta S_{V}\left[\mathrm{~J} \cdot \mathrm{m}^{-3} \cdot \mathrm{K}^{-1}\right]$ is the entropy of fusion per unit volume.

It was assumed that new grain consists only from $\alpha$ phase. However there is no pushing of elements considered at the initiation stage. This process and diffusion of elements in extradendritic liquid are taken into account since grain starts to grow.

\subsection{Dendrite growth rate}

Modelling of dendrite growth rate is very important issue. It was discussed by many authors $[13,14]$. As the effect of those analysis some dendrite growth rate models were developed. Mentioned models connects the dendrite tip growth rate with physicochemical parameters and solutal undercooling. In this work the following model was chosen $[15,10]$ :

$$
\frac{d R}{d \tau}=\frac{D_{S} \Delta S_{V}}{8 \sigma_{s l} Q}\left(\Delta T_{s}\right)^{2},
$$

where: $R[\mathrm{~m}]$ denotes dendrite spherical envelope radius; $D_{S}\left[\mathrm{~m}^{2} \cdot \mathrm{s}^{-1}\right]$ is diffusion in the liquid; $\sigma_{s l}\left[\mathrm{~J} \cdot \mathrm{m}^{-2}\right]$ is the solid/liquid interfacial energy; $Q[\mathrm{~K}]$ is the growth-restriction parameter and $\Delta T_{S}[\mathrm{~K}]$ is solutal undercooling.

In this case, $\Delta T_{S}$, is assumed to be only force for dendrite tip growth and it can be calculated as:

$$
\Delta T_{S}=T_{L}-T
$$


where temperature observed in element $V$ is calculated with heat balance equation:

$$
\frac{\partial T}{\partial \tau}=P+\frac{q}{c_{p} \rho}
$$

where: $T[\mathrm{~K}]$ is current medium temperature; $c_{p}\left[\mathrm{~J} \cdot \mathrm{kg}^{-1} \cdot \mathrm{K}^{-1}\right]$ is heat capacity; $q\left[\mathrm{~W} \cdot \mathrm{m}^{-3}\right]$ is latent heat of crystallization; $T_{L}[\mathrm{~K}]$ is liquidus temperature taken from phase diagram lines; $P\left[\mathrm{~K} \cdot \mathrm{s}^{-1}\right]$ is imposed cooling rate that can be described with any function or be set to constant $[3,10]$.

In numerical calculations time is divided into a series of isothermal steps. During each step temperature does not change, also liquid is spatially isothermal. In each time step the current solutal undercooling is calculated from phase diagram for temperature evaluated with Eq. (5). Solutal undercooling is then used for dendrite tip growth rate calculation, Eq. (3).

\subsection{Solute depletion length}

At every time step next increment of grain envelope radius, $R$, is calculated with Eq. (3). Then the flux of alloying element concentration caused by interface moving is determined, Figure 1 . In this Figure areas denoted $d C$ shows the alloying element pushing regions.

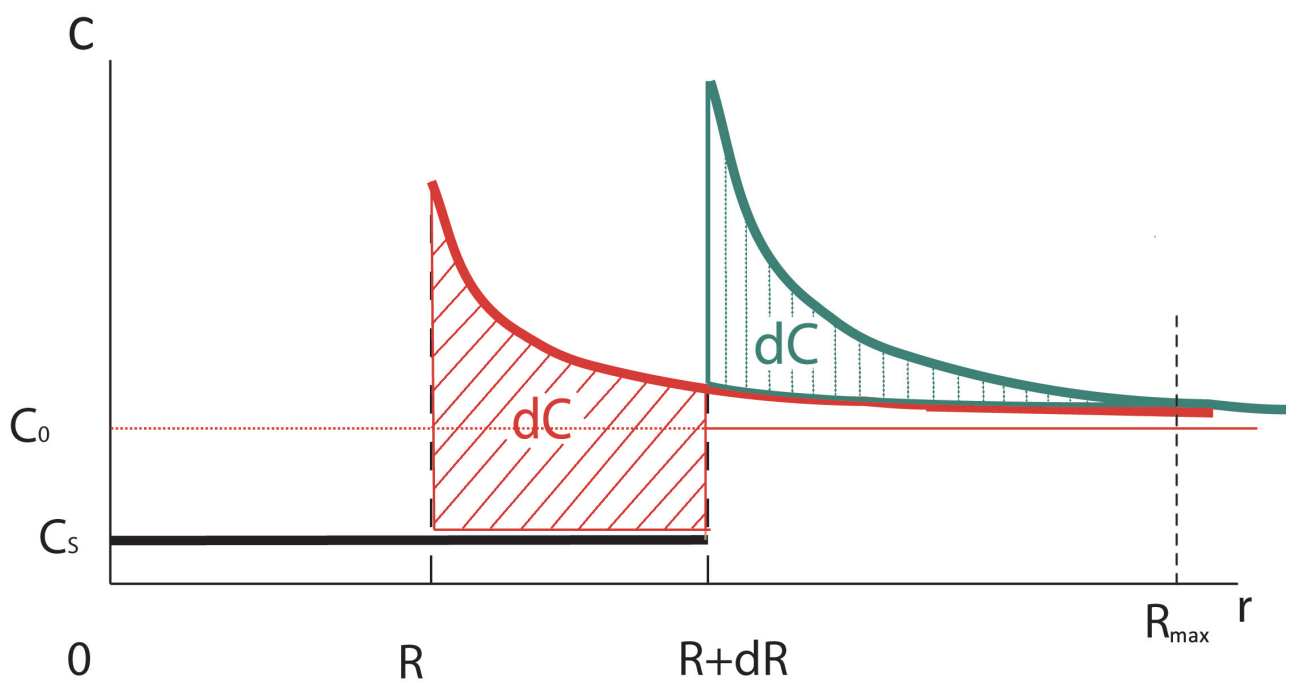

Fig. 1. Effect of dendrite growth on the alloying element concentrationin the liquid adjected to the dendrite envelope. Regions denoted $d C$ (skew lining) illustrate the area that is the base for alloying element concentration flux evaluation. The alloying element amount is calculated from region captured by growing dendrite and redistributed in melt after applying boundary condition, $d C$ (vertical lining) 
Distribution of alloying element in the liquid adjected to the dendrite tip is determined with modified Fick's law for spherical system [16]:

- in liquid:

$$
\left\{\begin{array}{l}
\frac{\partial C}{\partial \tau}=D_{S}\left(\frac{\partial^{2} C}{\partial r^{2}}+\frac{2}{r} \frac{\partial C}{\partial r}\right) \\
\left.\frac{\partial C}{\partial r}\right|_{r \rightarrow R}=-\frac{C_{L}-C_{S}}{D_{S}} \frac{d R}{d \tau}, \\
\left.\frac{\partial C}{\partial r}\right|_{r=R_{\max }}=0,
\end{array}\right.
$$

where: $C_{S}$ [wt.\%] is concentration on the interface taken from phase diagram for solidus line; $C_{L}$ [wt.\%] is the alloying element concentration on the interface taken from phase diagram for liquidus line.

Set of transfer equations Eq. (6) can be solved with numerical methods. For time derivative the same differential scheme as for Eq. (3) and (5) should be used. In the case of spatial derivatives modern approximation techniques can be used, for example Rank Controlled Differential Quadrature Method [17]. The computations accorded to this model with use of mentioned modern approximation techniques will be the subject of future work.

\section{CONCLUSIONS}

Presented model allows to predict growth rate of dendrite tip. It makes it also possible to determine the alloying element concentration in the solid and in the liquid adjected to the dendrite envelope, on the axis between dendrite centre and tip.

Prepared set of differential equations is ready prepared to be solve with numerical methods.

Described model will be a complement element while building more general nucleation and crystal growth model.

\section{Acknowledgements}

The authors acknowledge The European Community for financial support under Marie Curie Transfer of Knowledge grant No. MTKD-CT-2006-042468 (AGH No. 27.27.170.304). 


\section{REFERENCES}

[1] Maxwell I., Hellawell A.: A simple model for refinement during solidification, Acta Metallurgica, 1975, 23, 229-237

[2] Rappaz M., Thevoz P.H.: Solute diffusion model for equaxed dendritic growth, Acta Materialia, 1987, 35, 1487-1497

[3] Greer A.L., Bunn A.M., Tronche A., Evans P.V., Bristow D.J.: Modelling of inaculation of metallic melts: Application to grain refinement of aluminium by Al-Ti-B, Acta Materialia, 2000, 48, 2823-2835

[4] Fras E., Wiencek K., Gorny M., Lopez H.: Theoretical model for heterogeneous nucleation of grains during nucleation, Material Science and Technology, 2003, 19, 1653-1659

[5] Kapturkiewicz W., Fras E., Burbelko A.: Computer simulation of the austenitizing process in cast iron with pearlitic matrix, Materials Science and Engineering A, 2005, 413-414, 352-357

[6] Mirihange W.U., Browne D.J.: Combined analytical/numerical modelling of nucleation and growth during equaxed solidification under the influence of thermal convection. Computational Materials Science, 2009, 46, 777-784

[7] Gurgul D., Burbelko A.A.: Simulation of austenite and graphite growth in ductile iron by means of cellular automata, Archives of Metallurgy and Materials, 2010, 55, 53-60

[8] Lelito J., Żak P., Suchy J.S., Krajewski W.K., Krawiec H., Greer L., Schumacher P., Greer A.L., Haberl K., Dartak P.: Modelling the effect of $\mathrm{SiC}$ mass fraction on crystallization of magnesium metal matrix composite; AZ91/SiC, Inżynieria Materiałowa, 2010, 175, 703-707

[9] Dahle A.K., Arnberg L.: On the assumption of an additive effect of solute elements in dendrite growth, Materials Science and Engineering, 1997, A225, 38-46

[10] Quested T.E., Greer A.L.: Grain refinement of $\mathrm{Al}$ alloys: Mechanisms determining as-cast grain size in directional solidification, Acta Materialia. 2005, 53, 4643-4653

[11] Żak P., Lelito J., Suchy J.S., Krajewski W.K., Krawiec H., Haberl K., Schumacher P., Greer A.L., Shirzadi A., Gracz B.: Modelling the effect of $\mathrm{SiC}$ particle size on crystallization of magnesium metal matrix composite; AZ91/SiC, Inżynieria Materiałowa, 2010, 175, 699-702

[12] Mohanty P.S., Gruzleski J.E.: Mechanism of grain refinement in aluminium. Acta metallica and materialia, 1995, 43, 2001-2012

[13] Hunt J.D.: Steady state columnar and equiaxed growth of dendrites and eutectic, Materials Science and Engineering, 1984, 65, 75-83

[14] Kurz W., Fisher D.J.: Fundamentals of solidification, Zurich: Trans Tech Publications, 1992

[15] Burden M.H., Hunt J.D.: Cellular and dendritic growth II, Journal of Crystal Growth, 1974, 22, 109-116

[16] Fromm J.E.: An introduction to computer simulation in applied science, Abraham FA and Tiller WA, eds., 1970, Tomy Palo Alto Scientific Center Report No. 320-3269

[17] Żak P., Lelito J., Suchy J.S., Krajewski W.K.: Improving the heat transfer numerical solution accuracy with application of Rank Controlled Differential Quadrature Method [Poprawa dokładności przybliżonego rozwiązania problemu transportu ciepła poprzez zastosowanie metody kwadratur różniczkowych sterowanego rzędu], Monografia: „Polska metalurgia w latach 2006-2010”. Komitet Metalurgii PAN, Kraków, $2010,278-285$ (in polish)

Received

December 2010 